\title{
Towards Fast and Quantitative Modification of Large Gold Nanoparticles by Thiolated DNA: Scaling of Nanoscale Forces, Kinetics and the Need for Thiol Reduction
}

\author{
Xu Zhang ${ }^{\mathrm{a}, \mathrm{b}}$, Tony Gouriye ${ }^{\mathrm{c}}$, Kristian Göeken ${ }^{\mathrm{d}}$, Mark R. Servos ${ }^{\mathrm{b}}$, Ron Gill ${ }^{\mathrm{d}, *}$ and Juewen Liu ${ }^{\mathrm{a}, *}$ \\ a Department of Chemistry, Waterloo Institute for Nanotechnology, ${ }^{\mathrm{b}}$ Department of Biology, \\ University of Waterloo, Waterloo, Ontario, N2L 3G1, Canada. Fax: 519 7460435; Tel: 5198884567 \\ Ext. 38919; \\ E-mail: liujw@uwaterloo.ca
}

${ }^{\mathrm{c}}$ Institute for Life Science and Technology, Saxion University of Applied Sciences, Enschede, The Netherlands

\footnotetext{
${ }^{\mathrm{d}}$ Nanobiophysics Group, MIRA Institute for Biomedical Technology and Technical Medicine, University of Twente, Enschede, The Netherlands. Fax: +31 53 4891105; Tel: +31 53 4893067; E-mail: R.Gill@utwente.nl
}

This document is the Accepted Manuscript version of a Published Work that appeared in final form in The Journal of Physical Chemistry copyright (C) American Chemical Society after peer review and technical editing by publisher. To access the final edited and published work see Zhang, X., Gouriye, T., Göeken, K., Servos, M. R., Gill, R., \& Liu, J. (2013). Toward Fast and Quantitative Modification of Large Gold Nanoparticles by Thiolated DNA: Scaling of Nanoscale Forces, Kinetics, and the Need for Thiol Reduction. The Journal of Physical Chemistry C, 117(30), 15677-15684. https://doi.org/10.1021/jp403946x 


\begin{abstract}
We have recently reported on the fast and quantitative adsorption of DNA to 13 nm gold nanoparticles (AuNPs) at $\mathrm{pH}$ 3. This is in contrast to most traditional methods at neutral $\mathrm{pH}$, where the adsorption is both slow and requires high excess of DNA. Direct application of our protocol to large particles in many cases did not result in particles that are stable at high $(0.3 \mathrm{M})$ salt, and high excess of DNA was still required for the formation of stable particles. In this work we investigate the reasons for this limitation on the basis of kinetics and colloidal stability. Based on our investigation, fast and quantitative modification of large AuNPs is still possible, either by working at high particle concentration, or by using sonication. As we have shown that fast quantitative modification of large particles is possible, the preparation step of reduction and purification of the thiolated DNA becomes the rate limiting step in the whole AuNP-DNA conjugate protocol. However we show that this step is unnecessary when using our current protocol.
\end{abstract}

Keywords: Adsorption, colloid, nucleic acids, $\mathrm{pH}$, ionic strength 


\section{Introduction}

DNA-functionalized gold nanoparticles (DNA-AuNPs) have inspired and enabled many aspects of nanobiotechnology ranging from precise control of interparticle distance, ${ }^{1,2}$ directed materials synthesis, ${ }^{3}$ colorimetric biosensor development, ${ }^{4,5}$ surface enhanced spectroscopy, ${ }^{6}$ to drug delivery. ${ }^{7}$ Since the structural and molecular recognition property of DNA is coupled to the optical and electric property of AuNPs, this conjugate is also useful for answering fundamental nanoscale problems. ${ }^{8-13}$ Since its first report in 1996, many aspects of this conjugate have been extensively studied, including structure, ${ }^{14,15}$ assembly kinetics, ${ }^{16}$ thermodynamics, ${ }^{17,18}$ melting property, ${ }^{13,19}$ electrophoresis, ${ }^{20,21}$ and DNA conformation. ${ }^{22,23}$

Attaching thiolated DNA to AuNPs to achieve a stable conjugate is the first step for all downstream applications. This seemingly simple reaction based on the well-known thiol/gold chemistry turns out to be not very straightforward since both DNA and AuNPs are negatively charged. ${ }^{24,25}$ Normally citrate-capped AuNPs are dispersed in a very low salt buffer (e.g. with $\sim 10 \mathrm{mM}$ or lower $\mathrm{Na}^{+}$), resulting in a long Debye screening length and strong DNA repulsion. DNA adsorption can be promoted by adding salt. However, salt has three main effects. First, it diminishes the repulsion between DNA and AuNPs, thus leading to faster adsorption kinetics. Second, it diminishes the repulsion between DNA strands on the particle, leading to a higher loading of DNA. Third, it also diminishes the repulsion between the nanoparticles and thus it promotes AuNP aggregation. If a high concentration of $\mathrm{NaCl}$ is added all at once, AuNPs aggregate before a high density of DNA is attached. To solve this problem, Mirkin and co-workers invented a 'salt aging' method, where $\mathrm{NaCl}$ was gradually added over 1-2 days. ${ }^{26}$ At each $\mathrm{NaCl}$ concentration, a certain DNA density can be reached, allowing the AuNPs to survive the next small increment of salt. The DNA conformation is also changed from being parallel to the gold surface to an upright arrangement, providing more effective steric stabilization. ${ }^{27}$ It is interesting to note that planar gold surfaces (e.g. gold electrodes) have no colloidal stability problems and DNA loading is usually performed in $1 \mathrm{M}$ salt. ${ }^{28-30}$ 
While the direct salt aging method works well for $13 \mathrm{~nm}$ AuNPs, it often fails to work for larger AuNPs (e.g. 40-50 nm or larger). Even with very small increments of NaCl concentration, large AuNPs still aggregate sometimes. ${ }^{9}$ In recent years, a number of improvements have been made to achieve stable large AuNP conjugates. For example, surfactants were used to increase the salt stability of AuNPs although the slow salt aging was still performed. ${ }^{31,32}$ Alternatively, AuNPs can be stabilized by crowded polymers such as polyethylene glycol, where DNA can be attached. ${ }^{11}$ It is interesting to note that most of the procedures still required a large excess of DNA. For $13 \mathrm{~nm}$ AuNPs, only $~ 30 \%$ of added DNA was eventually attached and for $50 \mathrm{~nm}$ AuNPs, only 5\% of DNA was attached. In other words, more than $90 \%$ of DNA was discarded for large AuNPs. ${ }^{31}$

Recently, it was reported that thiolated DNA can be attached to AuNPs in a few minutes at pH 3. ${ }^{12,33}$ With this method, quantitative DNA adsorption was achieved for $13 \mathrm{~nm}$ AuNPs. For example, with a DNA:AuNP ratio of below 100:1, most DNA were adsorbed by AuNPs. The same procedure was not successful at $\mathrm{pH} 7$ using salt aging and AuNPs aggregated if the DNA concentration was low. This suggests that at $\mathrm{pH} 3$, the rate of DNA adsorption is enhanced such that the AuNPs have enough DNA on them to prevent AuNP aggregation at the salt addition/pH adjustment step. At $\mathrm{pH} 7$, a high DNA concentration is required for DNA adsorption to be fast enough to prevent AuNP aggregation. Herein, we explore whether fast and quantitative attachment of DNA to large AuNPs can be achieved at low $\mathrm{pH}$. This study has revealed an interesting scaling effect based on the size of AuNPs and offered insights into the fundamental reaction kinetics of DNA adsorption and thermodynamics of AuNP aggregation. As we have shown that fast quantitative modification of large particles is possible, the preparation step of reduction and purification of the thiolated DNA becomes the rate limiting step in AuNP-DNA conjugate preparation. However we show that this step is unnecessary when using the low pH modification protocol. 


\section{Materials and Methods}

Chemicals. DNA2 and DNA3 were purchased from IBA Lifesciences (Göttingen, Germany). All the other DNA samples were purchased from Integrated DNA Technologies (Coralville, IA) and were purified by standard de-salting (see Table 1 for sequences). $\mathrm{HAuCl}_{4}$, tris(2-carboxyethyl) phosphine hydrochloride (TCEP) and KCN were from Sigma-Aldrich. AuNPs $(13 \mathrm{~nm}$ ) were synthesized based on the standard citrate reduction procedures and its concentration was estimated to be $\sim 10 \mathrm{nM}$. AuNPs of $40 \mathrm{~nm}$ size were purchased from BBI international (Cardiff, UK). AuNPs of other sizes (20, 30, 50 and $100 \mathrm{~nm}$ diameter) were purchased from Ted Pella (Redding, CA), which distributes BBI AuNPs. Hydrochloric acid was purchased from VWR (Mississauga, ON). Sodium citrate, sodium chloride and 4-(2-hydroxyethyl) piperazine-1-ethanesulfonate (HEPES) were purchased from Mandel Scientific (Guelph, ON). Milli-Q water was used for all experiments.

Table 1. DNA sequences and modifications in this work.

\begin{tabular}{|l|l|}
\hline $\begin{array}{l}\text { DNA } \\
\text { name }\end{array}$ & DNA sequences (from $\mathbf{5}^{\prime}$ to $\mathbf{3}^{\prime}$ ') \\
\hline DNA1 & SH-CCCAGGTTCTCT-FAM \\
\hline DNA2a & SH-TTTTTGGTGGATAACGTCTTTCA \\
\hline DNA2b & SH-AAAAAAAAAGGTGGATAACGTCT \\
\hline DNA3 & ACGCCTTCTTGTTGGAAAAAAAAA -SH \\
\hline DNA4 & FAM-TTTTTTTTTTTT-SH \\
\hline DNA5 & SH-CCCAGGTTCTCT \\
\hline DNA6 & TTGTCGTTGCGT-SH \\
\hline DNA7 & ACGCAACGACAAAGAGAACCTGGG \\
\hline DNA8 & CCCAGGTTCTCTTTGTCGTTGCGT \\
\hline DNA9 & TCACAGATGCGT-Alexa Fluor 488 \\
\hline DNA10 & ACGCCTTCTTGTTGGAAAAAAAAA-HS \\
\hline DNA11 & CCAACAAGAAGGCGT AAGACGTTAT CCACC \\
\hline DNA12 & AGACGCGCTGGCTTCAGGTGCCAGTGTCCTTCGGGACGTGG \\
\hline
\end{tabular}

The effect of AuNP size on DNA adsorption and AuNP stability. Two hundred $\mu \mathrm{L}$ of AuNPs of various sizes and concentrations were mixed with $1.5 \times$ and $10 \times$ times of the theoretical capacity of DNA1 (see Table 2 for $1.5 \times$ ) and incubated for 30 min prior to the addition of $\mathrm{pH} 3$ citrate $\cdot \mathrm{HCl}$ buffer 
(final citrate concentration: $10 \mathrm{mM}$ ) to enhance the DNA adsorption. The color change of the AuNP solutions was recorded with a digital camera (Canon PowerShot SD1200 IS), as shown in Figure 1A of the paper.

Table 2: the experiment design for $1.5 \times$ DNA.

$\begin{array}{llllll}\text { AuNP size }(\mathbf{n m}) & 13 & 20 & 30 & 50 & 100 \\ \text { AuNP concentration: }(\mathbf{n M}) & 10 & 1.2 & 0.33 & 0.075 & 0.0093 \\ \text { AuNP }(\boldsymbol{\mu L}) & 100 & 100 & 100 & 300 & 300 \\ \text { DNA/AuNP ratio } & 120 & 300 & 1000 & 1500 & 5000 \\ \text { Final DNA }(\mathbf{n M}) & 1200 & 360 & 330 & 112.5 & 46.5 \\ \text { DNA volume }(\boldsymbol{\mu L}) & 2.2 & 0.7 & 0.6 & 0.6 & 0.3 \\ \text { DNA stock concentration }(\boldsymbol{\mu M}) & 54 & 54 & 54 & 54 & 54 \\ \text { pH } 3 \text { buffer }(\boldsymbol{\mu L}) & 2 & 2 & 2 & 6 & 6\end{array}$

Quantification of the DNA loading capacity. Since the adsorbed DNA was labeled with FAM (6carboxyfluorescein) fluorophore, the quantification of DNA loading was obtained by measuring the fluorescence of FAM-DNA released from AuNP with a small amount of KCN solution (final concentration: $20 \mathrm{mM} \mathrm{KCN}$ in the DNA-AuNP solution). KCN completely dissolved AuNPs to generate a clear solution. The quantification was performed using a fluorescence microplate reader (Infinite F200 PRO, Tecan) with the calibration curve developed by plotting the fluorescence intensity of each standard over the concentration series.

DNA adsorption kinetics. To measure DNA adsorption kinetics onto $50 \mathrm{~nm}$ AuNPs, $1 \mathrm{~mL} 50 \mathrm{~nm}$ AuNPs from BBI was concentrated 10 times by centrifugation at $6000 \mathrm{rpm}$ for $7 \mathrm{~min}(\mathrm{AuNP}=0.75 \mathrm{nM}$ after concentration). DNA9 $(18 \mu \mathrm{L}, 250 \mathrm{nM})$ was added to $70 \mu \mathrm{L}$ water and $10 \mu \mathrm{L}$ AuNPs $(0.75 \mathrm{nM}$, so DNA:AuNP $=600: 1)$ with a brief vortex. $2 \mu \mathrm{L}$ of the mixture was transferred into $98 \mu \mathrm{L}$ of $50 \mathrm{mM}$ HEPES ( $\mathrm{pH} 7.6$ ) in a 96-well plate to measure the initial fluorescence. Afterwards, $2 \mu \mathrm{L}$ citrate buffer (500 mM, either $\mathrm{pH} 3$ or $\mathrm{pH}$ 7) was added into the DNA-AuNP solution. At designated time points, 2 $\mu \mathrm{L}$ of solution was transferred to a fresh plate-well for fluorescence measurement. 
The rate of salt induced aggregation of different sized AuNPs. A UV-Vis spectrometer (Agilent 8453A) was used to record the aggregation kinetics of AuNPs of various sizes $(13,20,30,50$, and 100 $\mathrm{nm}$ ) in the presence of $50 \mathrm{mM} \mathrm{NaCl}$. Herein, the aggregation rate was depicted as the rate of color change, i.e., the change of extinction ratio at $650 \mathrm{~nm} / 520 \mathrm{~nm}$ for the AuNPs smaller than $100 \mathrm{~nm}$ and $800 \mathrm{~nm} / 570 \mathrm{~nm}$ for $100 \mathrm{~nm}$ AuNPs. For each measurement, $100 \mu \mathrm{L}$ of AuNP was added in a quartz micro-cuvette and the light absorbance at 520 and $650 \mathrm{~nm}$ (or 570 and $800 \mathrm{~nm}$ ) was measured before and after addition of $\mathrm{NaCl}$. The extinction ratios obtained at each time point were plotted against the time, as shown in Figure 2D of the paper.

Table 3: Experiment design for studying the effect of DNA concentration.

$\begin{array}{llllllllll}\text { DNA } & 0.5 \times & 1 \times & 1.5 \times & 2 \times & 3 \times & 5 \times & 10 \times & 20 \times & 30 \times \\ \text { DNA/AuNP ratio: } & 320 & 640 & 960 & 1280 & 1920 & 3200 & 6400 & 12800 & 19200 \\ \text { DNA final con }(\mathbf{n M}) & 24 & 48 & 72 & 96 & 144 & 240 & 480 & 960 & 1440 \\ \text { AuNP volume }(\boldsymbol{\mu L}) & 200 & 200 & 200 & 200 & 200 & 200 & 200 & 200 & 200\end{array}$

Effect of DNA concentration and sonication. The effect of DNA initial concentration (or initial DNA/AuNP ratios) on the AuNP (50 nm) stability during pH 3 buffer assisted DNA functionalization was evaluated (Figure 3). Herein, the initial DNA/AuNP ratios were set from low $(0.5 \times)$ to high $(30 \times)$ as illustrated in Table 3. To slow down the aggregation rate of AuNPs, pH 3 buffer was added in multiple steps instead of once. For a $200-\mu \mathrm{L}$ AuNP-DNA1 mixture, a total of $4 \mu \mathrm{L}$ of $\mathrm{pH} 3$ citrate buffer $(500 \mathrm{mM})$ was added in 4 steps. In each step, $1 \mu \mathrm{L}$ of $\mathrm{pH} 3$ buffer was added into the AuNPDNA solution with a brief vortex to mix it; there was 5-min incubation time between any two consecutive additions of $\mathrm{pH} 3$ buffer. Finally, the mixture was spun down at $5000 \mathrm{rpm}$ for 4 min and the supernatant $(190 \mu \mathrm{L})$ was removed. Afterwards, $190 \mu \mathrm{L}$ of $5 \mathrm{mM}$ HEPES buffer (pH 7.6) was added into each tube for a 3-5 min sonication (1510-MT, Bransonic sonicator, 70w, $42 \mathrm{kHz}$ ). The sample color was recorded by the digital camera and UV-Vis spectrometer. 
Effect of TECP treatment and purification. In this experiment, we compared the adsorption kinetics and capacity of DNA1 with and without TCEP treatment. For the TCEP treated DNA, we further studied if the purification is critical. The TCEP treatment of DNA was performed under pH $5(50 \mathrm{mM}$ acetate buffer) for $1 \mathrm{hr}$ at room temperature to cleave the disulfide bond (TCEP:DNA1 = 50:1). To remove TCEP and cleave the small thiol compound, the DNA was purified with a $\mathrm{C}_{18}$ Sep-Pak column and lyophilized. The lyophilized powder was then dissolved in $5 \mathrm{mM}$ HEPES buffer (pH 7.6) and the UV absorbance at $260 \mathrm{~nm}$ was used to measure the DNA concentration. Afterwards, AuNPs (13 and 50 $\mathrm{nm}$, respectively) were mixed with DNA1 (non-TCEP treatment, TCEP-treated-DNA1 without purification and purified TCEP-treated-DNA1). The initial ratios between DNA1 and $13 \mathrm{~nm}$ or $50 \mathrm{~nm}$ AuNPs were 100:1 and 960:1, respectively. At each time point (the time point was designated as 0 before adding the $\mathrm{pH} 3$ buffer into the mixture), $2-\mu \mathrm{L}$ mixture was transferred and mixed with $98 \mu \mathrm{L}$ of HEPES buffer (20 mM, pH 7.6) for fluorescence measurement with the microplate reader. The normalized fluorescence data over time were plotted to demonstrate the adsorption kinetics. Quantification of the capacity was performed as described above.

\section{Results and Discussion}

Effect of DNA and AuNP concentration. First, to have a systematic understanding of the AuNP size effect, we mixed AuNPs from $13 \mathrm{~nm}$ to $100 \mathrm{~nm}$ with thiolated DNA (DNA1) at $\sim 1.5 \times$ or $10 \times$ of the theoretical capacity. The theoretical capacity was taken from the literature based on the surfactantassisted salt-aging method. ${ }^{10}$ For example, each $50 \mathrm{~nm}$ AuNP is reported to load $\sim 640$ thiolated DNA $\left(8.1 \times 10^{12} \mathrm{DNA} / \mathrm{cm}^{2}\right)$, and $1.5 \times$ means a DNA-to-AuNP ratio of $960: 1$. On the other hand, $1.5 \times$ for 13 nm AuNPs equals to a ratio of 135:1. Next, a final of $10 \mathrm{mM}$ citrate buffer (pH 3) was added to accelerate DNA attachment. Only the color of $13 \mathrm{~nm}$ AuNPs remained red regardless of the DNA concentration but all the larger AuNPs aggregated with color changing to purple/blue for the $1.5 \times$ DNA 
samples (Figure 1A). Stable conjugate for 20 and $30 \mathrm{~nm}$ AuNPs were obtained with 10× excess of the DNA, while 50 and $100 \mathrm{~nm}$ AuNPs still aggregated even with a 10× DNA. Therefore, a large excess of DNA is needed to stabilize larger AuNPs. Similar observations have been made with the salt aging method at pH 7 after 2-day incubation, where non-aggregated AuNPs were achieved only at DNA2ato-AuNP (40 nm) ratios of 60,000:1 and above ( 150× excess of DNA, see Figure S1 of Supporting Information).

To quantitatively understand the effect of AuNP size, we quantified the adsorbed DNA after centrifugation, removal of the supernatant DNA, repeated washing, and dissolving the AuNPs with $\mathrm{KCN}$. As shown in Figure 1B, the number of attached DNA was still quite high even with $1.5 \times$ DNA concentration (Figure 1B). For example, $50 \mathrm{~nm}$ AuNPs adsorbed 406 DNA at 1.5× and 553 DNA at $10 \times($ Figure $1 \mathrm{~B})$, where the full capacity after long-term and high concentration salt aging is $640 .{ }^{10}$ This is true for all sized AuNPs that increasing the initial DNA concentration from $1.5 \times$ to $10 \times$ of the capacity only moderately increased the final loading but the effect on AuNP stability was quite pronounced. Based on the above experiments, two possible reasons were proposed to explain the need of a large excess of DNA for large AuNPs. First, larger AuNPs might be more susceptible to salt and they aggregate faster than the smaller ones upon salt addition. Second, we noticed that in the literature, a similar DNA concentration (e.g. $\sim 1-6 \mu \mathrm{M}$ ) was used regardless of AuNP size. It might be that certain DNA adsorption kinetics are required to prevent AuNP aggregation, regardless of AuNP size. These hypotheses were individually tested. To confirm the effect of low $\mathrm{pH}$ loading on large AuNPs, we measured the DNA adsorption kinetics onto $50 \mathrm{~nm}$ AuNPs (Figure 1C). A fluorophore-labeled DNA (DNA9) was mixed with AuNPs at a ratio of 600:1. We observe two main effects of low pH adsorption. One is that the initial adsorption kinetics is faster. The second is that the final DNA concentration on the surface is higher (we see about $3 \times$ as much reduction in fluorescence, indicating that about $3 \times$ as much DNA was adsorbed on the particle). We attribute both effects to the fact that at low $\mathrm{pH}$, the DNA 
is less negatively charged because some of the bases (A and C) are protonated, which reduced DNAparticle repulsion and DNA-DNA repulsion on the particle surface.
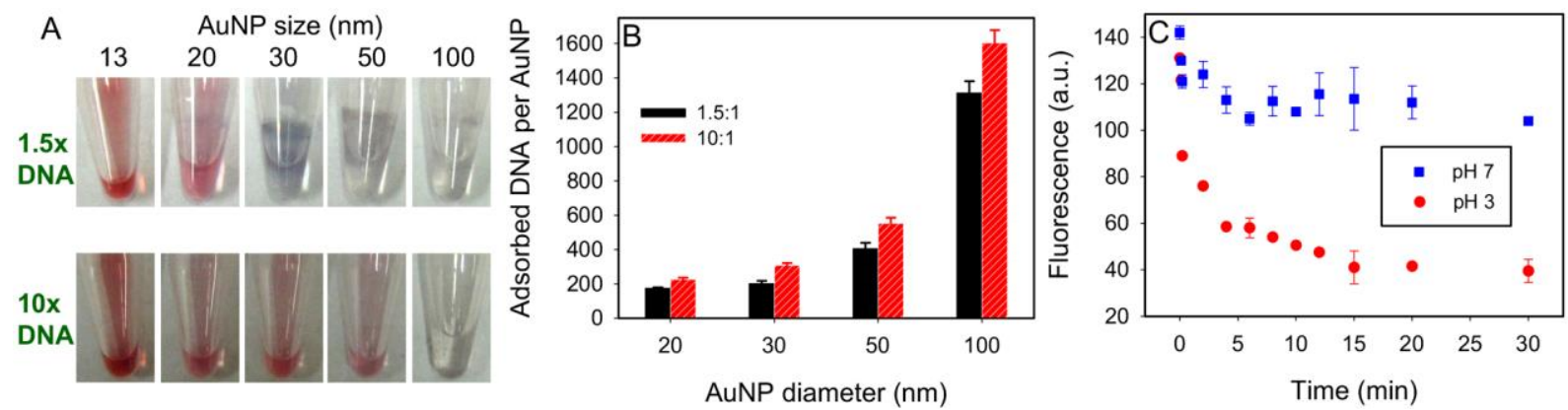

Figure 1. (A) Photographs of AuNPs of various sizes incubated with DNA1 of either $1.5 \times$ or $10 \times$ of the full capacity at each AuNP size followed by adding $10 \mathrm{mM} \mathrm{pH} 3$ citrate buffer and $70 \mathrm{mM} \mathrm{NaCl}$. (B) DNA adsorption capacity of AuNPs for the samples in (A). (C) Fluorescence intensity of dyelabeled DNA (DNA9) as a function of incubation time with $50 \mathrm{~nm}$ AuNPs, at pH=7 (squares) and $\mathrm{pH}=3$ (spheres). The DNA to particle ratio was 600:1.

It needs to be pointed out that the concentration of larger AuNPs from commercial sources are usually much lower compared to that of the smaller ones (Figure 2A). For example, the $50 \mathrm{~nm}$ AuNPs from $\mathrm{BBI}$ are $0.075 \mathrm{nM}$ while our $13 \mathrm{~nm}$ AuNPs are $\sim 10 \mathrm{nM}$. At the same time, the extinction coefficient of larger AuNPs are much higher (e.g. $2.7 \times 10^{8}$ and $1.5 \times 10^{10} \mathrm{M}^{-1} \mathrm{~cm}^{-1}$ for 13 and $50 \mathrm{~nm}$ AuNPs, respectively), resulting in a similar optical density. In order to follow the aggregation kinetics, we used the ratio between the plasmon-plasmon interaction peak (at $650 \mathrm{~nm}$ for $<100 \mathrm{~nm}$ particles, and 800 for $100 \mathrm{~nm}$ particles) and the single particle plasmon peak (at $520 \mathrm{~nm}$ for the smaller particles and $570 \mathrm{~nm}$ for the $100 \mathrm{~nm}$ particles). The rise of the plasmon-plasmon interaction peak as particles aggregate is the cause of the apparent blue color which is usually seen during aggregation. To compare the rate of aggregation, AuNPs of different sizes were challenged with $50 \mathrm{mM} \mathrm{NaCl}$ and their UV-vis 
spectra were followed as a function of time. As shown in Figure 2D, addition of salt induced an immediate color change at all particle sizes. The rate of change appeared to be just slightly slower for larger AuNPs, which might be related to their very low concentrations. It is interesting to notice that 30 nm AuNPs did not reach the high ratio as the other AuNP sizes did. Overall, with the practical AuNP concentrations from the commercial source, the rate of salt-induced change in extinction is comparable for AuNPs of various sizes. Therefore, our first hypothesis that large particles require a large excess of DNA because larger AuNPs aggregate faster was not supported. It is important to re-emphasize here that while extinction shift can give an indication on the aggregation, they are not direct measurement of the aggregation, as the extinction shift depend also on the size of the particles and the size of the aggregate. For example, it may take many $13 \mathrm{~nm}$ AuNPs to aggregate before a similar extinction change can be achieved compared to a dimer formation with $100 \mathrm{~nm}$ AuNPs. ${ }^{34}$
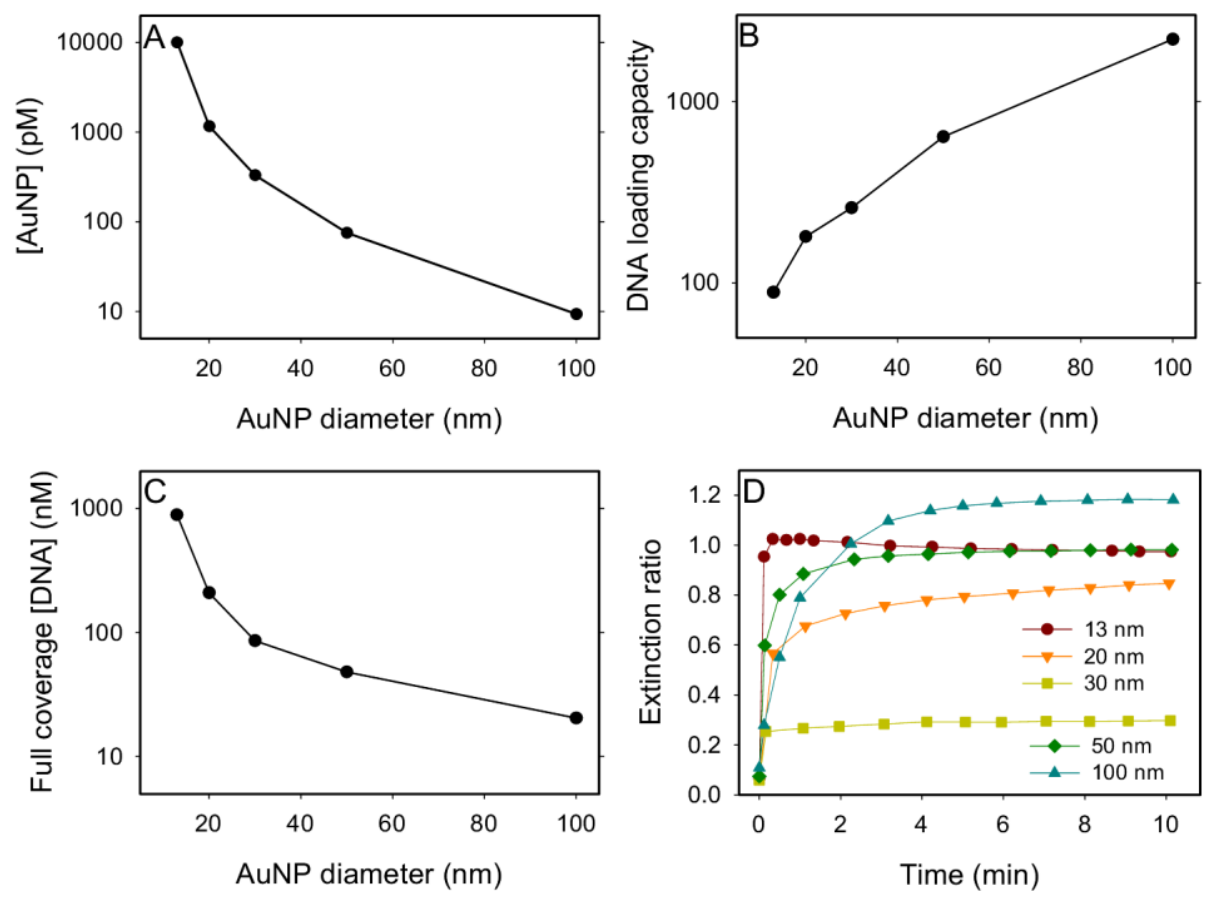

Figure 2. (A) AuNP concentration from BBI (other than $13 \mathrm{~nm}$ AuNPs) as a function of size; (B) the DNA loading capacity on each sized AuNP, and (C) the calculated DNA concentration required to fully cover AuNP surface (red line). The units for each curve are in the figure legend. (D) Rate of AuNP 
color change for different sized AuNPs after addition of $50 \mathrm{mM} \mathrm{NaCl}$ (added at time zero). The extinction ratios are at $650 \mathrm{~nm} / 520 \mathrm{~nm}$ for all the AuNPs except for $100 \mathrm{~nm}$, which used $800 \mathrm{~nm} / 570$ nm.

For a successful conjugation reaction, the rate of DNA adsorption needs to significantly surpass that of AuNP aggregation. Based on the concentration of each sized AuNP (Figure 2A) and the loading capacity (Figure 2B), we calculated the DNA concentration for quantitative adsorption (Figure 2C). To achieve quantitative adsorption, the DNA added needs to be 20 fold lower for $50 \mathrm{~nm}$ AuNPs compared to that for $13 \mathrm{~nm}$ AuNPs. Based on the mass action law, the initial DNA adsorption kinetics is linearly proportional to the concentration of DNA. Therefore, under the quantitative DNA adsorption condition, DNA adsorption is twenty times slower for the $50 \mathrm{~nm}$ AuNPs. Since we estimated from our extinction data that the speed of aggregation is similar in all AuNP sizes, the low initial DNA concentration could explain that large AuNPs tend to aggregate under quantitative DNA adsorption conditions. Note that it is difficult to quantitatively compare the rate of DNA adsorption with the rate of AuNP aggregation since only extinction changes are experimentally measured and it is difficult to correlate directly such changes with the rate of aggregation. Ideally, we aim to completely suppress the aggregation of AuNPs to achieve high quality conjugates.

By performing the adsorption reaction at $\mathrm{pH} 3$, the rate of DNA adsorption is faster and this allows quantitative adsorption for $13 \mathrm{~nm}$ AuNPs (e.g. 1 $\mu \mathrm{M}$ DNA with $10 \mathrm{nM}$ AuNPs). ${ }^{12}$ However, it is still not fast enough if the initial DNA concentration is too low. If this hypothesis is true, one way to solve this problem is to increase the concentration of large AuNPs so that a similar initial DNA concentration as that for smaller AuNPs can be used while still maintaining the DNA concentration for quantitative DNA adsorption. To test this, $40 \mathrm{~nm}$ AuNPs were centrifuged at $6000 \mathrm{~g}$ for $10 \mathrm{~min}$. After removal of the supernatant solution, the AuNPs were concentrated by 100 times. With a DNA2b:AuNP 
ratio of $666: 1(\sim 1.5 \times$ of full capacity), stable conjugates were obtained, which can survive in $300 \mathrm{mM}$ $\mathrm{NaCl}$ (Figure S2, green curve). Under this condition, the initial DNA concentration was $10 \mu \mathrm{M}$, which is similar to that typically used for DNA attachment to $13 \mathrm{~nm}$ AuNPs (e.g. $\sim 3 \mu \mathrm{M}$ DNA). This experiment also suggests that colloidal AuNP aggregation is less dependent on its own concentration, but DNA adsorption kinetics is highly related to the DNA concentration.

Sonication assisted DNA attachment. While the AuNP concentrating method works, it remains intriguing that large AuNPs tend to aggregate even with a relatively high DNA loading capacity as shown in Figure 1. From the surface force perspective, the van der Waals force is the main attractive force initially since it is relatively long-ranged. If a high DNA density cannot be quickly achieved to force DNA to adopt an upright conformation, AuNPs can approach each other with the help of the added salt to a very short distance, where van der Waals force dominates to induce aggregation. Since van der Waals force scales linearly with AuNP size, ${ }^{35}$ this may explain that larger AuNPs are more difficult to functionalize in general.

We already know from Figure 1B that the DNA loading capacity is quite high with even only $1.5 \times$ DNA. With the above analysis, we reason that it is possible that on the surface of the particles there are enough DNA molecules that charge repulsion is strong enough to prevent irreversible aggregation. However, considering the interplay between electrostatic repulsion and van der Waals attraction according to DLVO theory, there can be a secondary minimum in the energy distance curve, which can be a source for flocculation (i.e. reversible aggregation). Since this secondary minimum depth increases with increasing particle size ${ }^{36}$ this can explain the higher tendency of flocculation with increasing particle size. In our hypothesis is true, and this is actually flocculation, we should be able to redisperse the particles by moving them to an lower salt solution (as this reduced the depth of the energy well) and use sonication to give the particle enough energy to redisperse. To test this, we mixed DNA and $50 \mathrm{~nm}$ AuNPs at various ratios followed by adding the $\mathrm{pH} 3$ buffer and salt. As shown in 
Figure 3A, the color of AuNPs remained red only with higher than 10× DNA (e.g. DNA1:AuNP = 6400:1). After centrifugation and removal of the supernatant, the aggregates were dispersed in $5 \mathrm{mM}$ HEPES (pH 7.6). After sonication for 2-5 min, the AuNPs turned red for most of the samples. The UVvis spectra of these samples were measured (Figure 3B,C). After sonication, good stability was achieved when more than $3 \times$ DNA was used. It deserves noting that DNA could continue to be attached to AuNPs even after the samples were aggregated. Therefore, the AuNPs are likely to have higher stability after sonication because of the higher DNA density. Mirkin and co-workers have used sonication in surfactant-assisted DNA attachment and they also observed that sonication was more effective on large AuNPs. ${ }^{31}$ We reason that sonication might be playing a similar role in both systems. For the case of high excess of DNA, or using highly concentrated particles with quantitative $(1.5 \times)$ DNA amounts, we expect that DNA adsorption would be so fast as to create a dense layer of standing DNA strands. Under this condition there is both a stronger electrostatic repulsion and a steric hindrance effect which together lead to a very shallow secondary minimum that might be within the thermal noise (kT) and therefore no flocculation is observed. We have also confirmed that DNA attachment using highly concentrated particles lead to functional particles (Figure S3, S4).

It needs to be pointed out that the $\mathrm{pH} 3$ method relies on the protonation of DNA bases (e.g. A and $\mathrm{C}$ ). Therefore if the sequence is rich in $\mathrm{T}$ or $\mathrm{G}$, this method might not work. For example, we

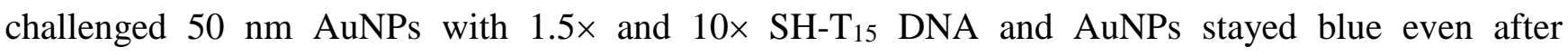
sonication. At $\mathrm{pH} 3$ the adsorption kinetics were slightly improved for this DNA but the DNA loading capacity was low. To achieve high loading capacity, a very high initial DNA concentration is required (e.g. 50×, see Figure S5). Even under such conditions, however, AuNPs remained unstable. Therefore, the traditional 'salt aging' method needs to be used. So far, we have provided two solutions that may achieve quantitative DNA adsorption for large AuNPs. One is to enrich AuNPs to a much higher concentration and the other is sonication and these two methods can be used at the same time. 

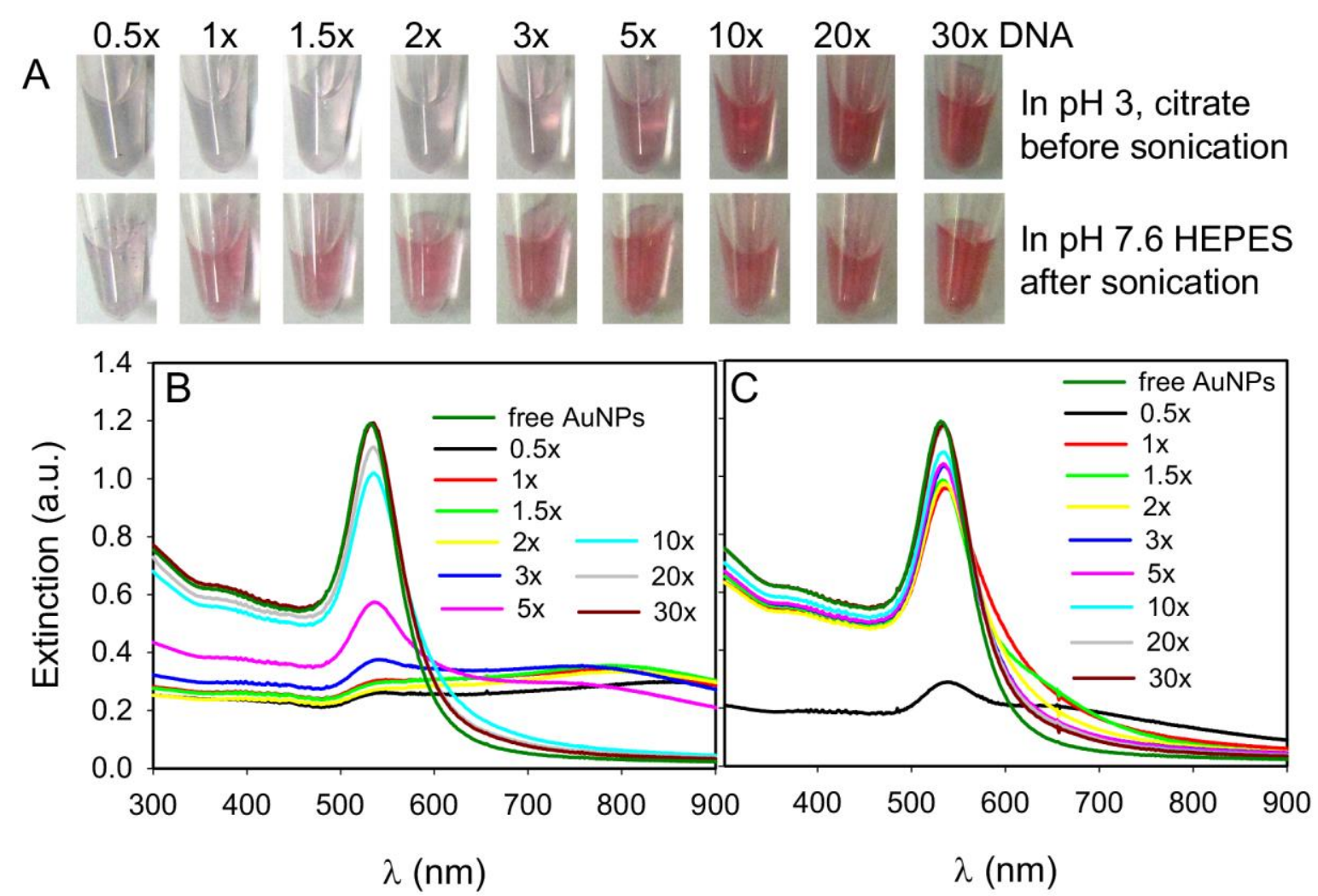

Figure 3. (A) Photographs of $50 \mathrm{~nm}$ AuNPs mixed with various concentrations of DNA at $\mathrm{pH} 3$ (10 $\mathrm{mM}$ citrate buffer with $70 \mathrm{mM} \mathrm{NaCl}$ ), and the same samples after centrifugation, re-dispersing in $5 \mathrm{mM}$ HEPES, pH 7.6 and sonication. UV-vis spectra of the samples in (A) before (B) and after (C) the buffer exchange and sonication treatment.

Effect of TCEP treatment. In our quest to find a method to create stable DNA-AuNP conjugates based on large particles, we have shown that a fast modification step is possible. However, once the modification step itself can be rapid, the preparation of the thiolated DNA, which usually involved a reduction step and a purification step becomes the rate-limiting step in the preparation of the DNAAuNP conjugates. Commercial thiolated DNAs are capped by small alkanethiol molecules and typically before mixing with AuNPs the disulfide is cleaved by adding a reducing agent such as 
dithiothreitol (DTT) or Tris(2-carboxyethyl) phosphine hydrochloride (TCEP). ${ }^{26,37,38}$ Such reducing agents, especially DTT, are usually used in excess to achieve complete reduction of the DNA. All the non-DNA compounds in the system can be considered as impurities. A purification step is often followed to remove the reducing agents and the cleaved alkanethiol compound. This reducing protocol has been well established since 1996 and has been faithfully followed by most groups working on this system. It is interesting to note that no report was found in the literature to understand the effect of this reducing reaction in the context of AuNP functionalization. Surprisingly, we found it is actually not necessary for most applications as described below.

We consider that most of the impurities could compete with DNA for AuNP surface. In particular, small thiol compounds diffuse faster than DNA and they are charge neutral. Since they are not repelled by AuNPs, small thiol compounds are likely to reach the surface of AuNPs before DNA. We compared the adsorption kinetics and capacity of non-reduced thiolated DNA, and TCEP-reduced DNA with and without downstream purification (i.e. TCEP and thiol removed). For both $13 \mathrm{~nm}$ and 50 nm AuNPs, we observed a similar adsorption rate (Figure 4A, B). Next the adsorption capacity was compared and again similar results were obtained (Figure 4C, D). TCEP itself does not adsorb to gold surface, as reported by Georgiadis et al. ${ }^{39}$ Therefore, it should not affect the DNA adsorption kinetics or capacity.

Based on the classical SAM structure of $\mathrm{Au}(111)(\sqrt{3} \times \sqrt{3}) \mathrm{R} 30^{\circ}-\mathrm{CH}_{3}\left(\mathrm{CH}_{2}\right)_{\mathrm{n}} \mathrm{SH}$, the selfassembled monolayer (SAM) overlayer forms a hexagonal 2D lattice with the lattice constant being $\sqrt{ } 3 \mathrm{a}=\sqrt{ } 3 \times 0.408 \mathrm{~nm}=0.707 \mathrm{~nm}$. Therefore, each $13 \mathrm{~nm}$ diameter AuNP can adsorb 1225 small thiol molecules. Since the typical DNA density on AuNP surface is below one hundred, there should be sufficient room to accommodate small thiolated compounds from the reaction.

It is well-known in the early studies of self-assembled monolayers (SAMs) that disulfides can also be cleaved by gold surfaces, ${ }^{40,41}$ and therefore it is not surprising that there is little effect if not 
performing the reducing reaction. We postulate that the real function of the reducing reaction in the early days was the purification step that removes other impurities from the DNA synthesis reactions. If not carefully desalted, those impurities might cause AuNP aggregation. To achieve the highest possible quality of DNA-AuNP conjugates, a thorough reduction of the disulfide bond and a careful removal of the impurities might still be helpful to eliminate any possible interference.
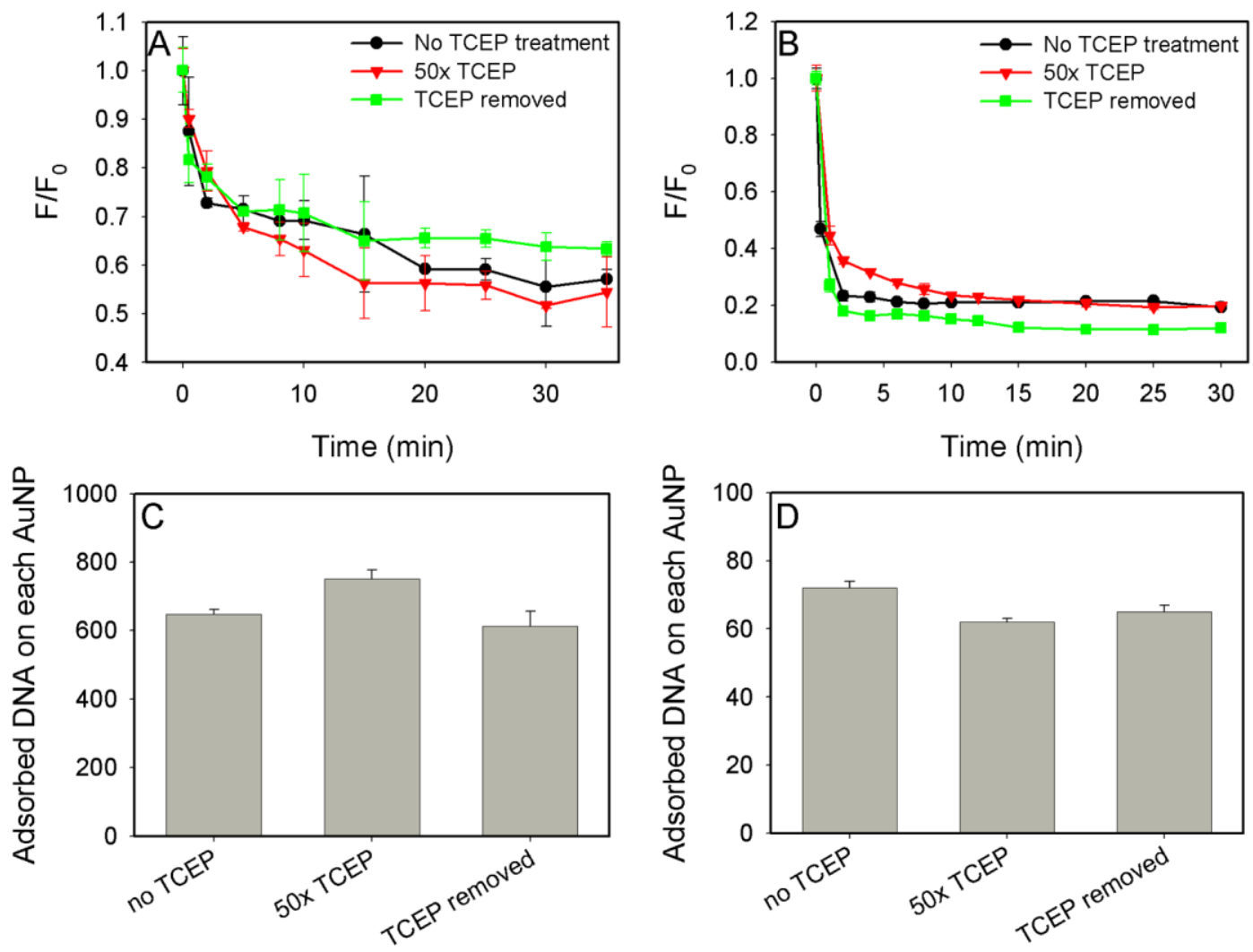

Figure 4. The effect of TCEP treatment. Fluorescence quenching indicating DNA adsorption onto 50 nm (A) and 13 nm (B) AuNPs. DNA adsorption capacity for $50 \mathrm{~nm}$ (C) and $13 \mathrm{~nm}$ (D) AuNPs.

\section{Conclusions}

In summary, while the DNA-AuNP system has been studied by many groups for more than 15 years, there are still many questions to be answered. In this study, we have addressed the kinetics of DNA adsorption versus AuNP aggregation as a function of the size of AuNPs. While the apparent 
aggregation rate of AuNPs is quite independent of their sizes as judged by the color change, quantitative DNA adsorption becomes more difficult to achieve for larger AuNPs due to their extremely low concentrations. Intermolecular force scaling with AuNP size appears to also be playing an important role. These understandings have resulted in two types of solutions to achieve quantitative DNA adsorption. Finally, we found that the DNA activation step typically performed is unnecessary.

\section{Acknowledgement}

Funding for this work is from the University of Waterloo, the Canadian Foundation for Innovation, and the Natural Sciences and Engineering Research Council (NSERC) of Canada, the Canadian Institutes of Health Research (CIHR) and the Early Researcher Award from the Ontario Ministry of Research and Innovation. The work of K. G. was funded by the Netherlands Technology Foundation STW (STW-project no. 11818).

Supporting Information Available. Additional UV-vis spectra, DNA-directed AuNP assembly, polyT DNA attachment. This information is available free of charge via the Internet at http://pubs.acs.org

\section{References:}

(1) Mirkin, C. A.; Letsinger, R. L.; Mucic, R. C.; Storhoff, J. J. A DNA-Based Method for Rationally Assembling Nanoparticles into Macroscopic Materials. Nature 1996, 382, 607-609.

(2) Alivisatos, A. P.; Johnsson, K. P.; Peng, X.; Wilson, T. E.; Loweth, C. J.; Bruchez, M. P., Jr;

Schultz, P. G. Organization of 'Nanocrystal Molecules' Using DNA. Nature 1996, 382, 609-611.

(3) Storhoff, J. J.; Mirkin, C. A. Programmed Materials Synthesis with DNA. Chem. Rev. 1999, 99, 1849-1862.

(4) Rosi, N. L.; Mirkin, C. A. Nanostructures in Biodiagnostics. Chem. Rev. 2005, 105, 1547-1562. 
Zhao, W.; Brook, M. A.; Li, Y. Design of Gold Nanoparticle-Based Colorimetric Biosensing Assays. ChemBioChem 2008, 9, 2363-2371.

(6) Qian, X. M.; Zhou, X.; Nie, S. M. Surface-Enhanced Raman Nanoparticle Beacons Based on Bioconjugated Gold Nanocrystals and Long Range Plasmonic Coupling. J. Am. Chem. Soc. 2008, 130, 14934-14935.

(7) Giljohann, D. A.; Seferos, D. S.; Daniel, W. L.; Massich, M. D.; Patel, P. C.; Mirkin, C. A. Gold Nanoparticles for Biology and Medicine. Angew. Chem. Int. Ed. 2010, 49, 3280-3294.

(8) Storhoff, J. J.; Lazarides, A. A.; Mucic, R. C.; Mirkin, C. A.; Letsinger, R. L.; Schatz, G. C. What Controls the Optical Properties of DNA-Linked Gold Nanoparticle Assemblies? J. Am. Chem. Soc. 2000, 122, 4640-4650.

(9) Jin, R.; Wu, G.; Li, Z.; Mirkin, C. A.; Schatz, G. C. What Controls the Melting Properties of DNA-Linked Gold Nanoparticle Assemblies? J. Am. Chem. Soc. 2003, 125, 1643-1654.

(10) Hill, H. D.; Millstone, J. E.; Banholzer, M. J.; Mirkin, C. A. The Role Radius of Curvature Plays in Thiolated Oligonucleotide Loading on Gold Nanoparticles. ACS Nano 2009, 3, 418424.

(11) Zhang, X.; Servos, M. R.; Liu, J. Ultrahigh Nanoparticle Stability against Salt, Ph and Solvent with Retained Surface Accessibility Via Depletion Stabilization. J. Am. Chem. Soc. 2012, 134, 9910-9913.

(12) Zhang, X.; Servos, M. R.; Liu, J. Instantaneous and Quantitative Functionalization of Gold Nanoparticles with Thiolated DNA Using a pH-Assisted and Surfactant-Free Route. J. Am. Chem. Soc. 2012, 134, 7266-7269.

(13) Smith, B. D.; Dave, N.; Huang, P.-J. J.; Liu, J. Assembly of DNA-Functionalized Gold Nanoparticles with Gaps and Overhangs in Linker DNA. J. Phys. Chem. C 2011, 115, 78517857. 
(14) Harris, N. C.; Kiang, C. H. Disorder in DNA-Linked Gold Nanoparticle Assemblies. Phys. Rev. Lett. 2005, 95, 046101.

(15) Yan, W. J.; Xu, L. G.; Xu, C. L.; Ma, W.; Kuang, H.; Wang, L. B.; Kotov, N. A. Self-Assembly of Chiral Nanoparticle Pyramids with Strong R/S Optical Activity. J. Am. Chem. Soc. 2012, 134, 15114-15121.

(16) Maye, M. M.; Nykypanchuk, D.; van der Lelie, D.; Gang, O. A Simple Method for Kinetic Control of DNA-Induced Nanoparticle Assembly. J. Am. Chem. Soc. 2006, 128, 14020-14021.

(17) Lytton-Jean, A. K. R.; Mirkin, C. A. A Thermodynamic Investigation into the Binding Properties of DNA Functionalized Gold Nanoparticle Probes and Molecular Fluorophore Probes. J. Am. Chem. Soc. 2005, 127, 12754-12755.

(18) $\mathrm{Xu}, \mathrm{J}$.; Craig, S. L. Thermodynamics of DNA Hybridization on Gold Nanoparticles. J. Am. Chem. Soc. 2005, 127, 13227-13231.

(19) Sikder, M. D. H.; Gibbs-Davis, J. M. The Influence of Gap Length on Cooperativity and Rate of Association in DNA-Modified Gold Nanoparticle Aggregates. J. Phys. Chem. C 2012, 116, 11694-11701.

(20) Pellegrino, T.; Sperling, R. A.; Alivisatos, A. P.; Parak, W. J. Gel Electrophoresis of Gold-DNA Nanoconjugates. J. Biomed. Biotechnol. 2007, 2007, 26796.

(21) Sandstrom, P.; Akerman, B. Electrophoretic Properties of DNA-Modified Colloidal Gold Nanoparticles. Langmuir 2004, 20, 4182-4186.

(22) Brown, K. A.; Park, S.; Hamad-Schifferli, K. Nucleotide-Surface Interactions in DNAModified Au-Nanoparticle Conjugates: Sequence Effects on Reactivity and Hybridization. $J$. Phys. Chem. C 2008, 112, 7517-7521.

(23) Park, S.; Brown, K. A.; Hamad-Schifferli, K. Changes in Oligonucleotide Conformation on Nanoparticle Surfaces by Modification with Mercaptohexanol. Nano Lett. 2004, 4, 1925-1929. 

Gold Nanoparticles. Langmuir 2012, 28, 3896-3902.

(25) Liu, J. Adsorption of DNA onto Gold Nanoparticles and Graphene Oxide: Surface Science and Applications. Phys. Chem. Chem. Phys. 2012, 14, 10485-10496.

(26) Storhoff, J. J.; Elghanian, R.; Mucic, R. C.; Mirkin, C. A.; Letsinger, R. L. One-Pot Colorimetric Differentiation of Polynucleotides with Single Base Imperfections Using Gold Nanoparticle Probes. J. Am. Chem. Soc. 1998, 120, 1959-1964.

(27) Cutler, J. I.; Auyeung, E.; Mirkin, C. A. Spherical Nucleic Acids. J. Am. Chem. Soc. 2012, 134, 1376-1391.

(28) Herne, T. M.; Tarlov, M. J. Characterization of DNA Probes Immobilized on Gold Surfaces. $J$. Am. Chem. Soc. 1997, 119, 8916-8920.

(29) Peterson, A. W.; Heaton, R. J.; Georgiadis, R. M. The Effect of Surface Probe Density on DNA Hybridization. Nucleic Acids Res. 2001, 29, 5163-5168.

(30) Petrovykh, D. Y.; Kimura-Suda, H.; Whitman, L. J.; Tarlov, M. J. Quantitative Analysis and Characterization of DNA Immobilized on Gold. J. Am. Chem. Soc. 2003, 125, 5219-5226.

(31) Hurst, S. J.; Lytton-Jean, A. K. R.; Mirkin, C. A. Maximizing DNA Loading on a Range of Gold Nanoparticle Sizes. Analytical Chemistry 2006, 78, 8313-8318.

(32) Zu, Y.; Gao, Z. Facile and Controllable Loading of Single-Stranded DNA on Gold Nanoparticles. Anal. Chem. 2009, 81, 8523-8528.

(33) Zhang, X.; Servos, M. R.; Liu, J. Fast pH-Assisted Functionalization of Silver Nanoparticles with Monothiolated DNA. Chem. Comm. 2012, 48, 10114-10116.

(34) Lang, N. J.; Liu, B.; Zhang, X.; Liu, J. Dissecting Colloidal Stabilization Factors in Crowded Polymer Solutions by Forming Self-Assembled Monolayers on Gold Nanoparticles. Langmuir 2013. 
(35) Bishop, K. J. M.; Wilmer, C. E.; Soh, S.; Grzybowski, B. A. Nanoscale Forces and Their Uses in Self-Assembly. Small 2009, 5, 1600-1630.

(36) Lyklema, H., 3 Pair Interactions. In Fundamentals of Interface and Colloid Science, Lyklema, J., Ed. Academic Press: 2005; Vol. Volume 4, pp 3.1-3.190.

(37) Liu, J.; Lu, Y. Preparation of Aptamer-Linked Gold Nanoparticle Purple Aggregates for Colorimetric Sensing of Analytes. Nat. Protoc. 2006, 1, 246-252.

(38) Burns, J. A.; Butler, J. C.; Moran, J.; Whitesides, G. M. Selective Reduction of Disulfides by Tris(2-Carboxyethyl)Phosphine. J. Org. Chem. 1991, 56, 2648-2650.

(39) Georgiadis, R.; Peterlinz, K. P.; Peterson, A. W. Quantitative Measurements and Modeling of Kinetics in Nucleic Acid Monolayer Films Using SPR Spectroscopy. J. Am. Chem. Soc. 2000, $122,3166-3173$.

(40) Nuzzo, R. G.; Fusco, F. A.; Allara, D. L. Spontaneously Organized Molecular Assemblies .3. Preparation and Properties of Solution Adsorbed Monolayers of Organic Disulfides on Gold Surfaces. J. Am. Chem. Soc. 1987, 109, 2358-2368.

(41) Nuzzo, R. G.; Allara, D. L. Adsorption of Bifunctional Organic Disulfides on Gold Surfaces. $J$. Am. Chem. Soc. 1983, 105, 4481-4483. 